\title{
De personagem a editor: vozes negras na literatura infanto-juvenil
}

Heloísa Pires Lima

Escritora (São Paulo, Brasil)

RESUMO: NESTE ENSAIO, CONFORME SE VERÁ, EXPRESSÕES LITERÁRIAS VOLTADAS PARA O PÚBLICO INFANTIL E JUVENIL ELEGEM ALGUNS ASPECTOS QUE REDIMENSIONAM UMA PERCEPÇÃO MAIS ABRANGENTE DO TEMA. POR EXEMPLO, O PONTO DE VISTA PARA CONSTRUIR MODELOS DE HUMANIDADE INDICA O EXAME DA REPRESENTAÇÃO DE AFRICANOS NUMA OBRA DE JÚLIO VERNE. O PROTAGONISMO DO EDITOR PAULA BRITO E A BIBLIOTECA VOLTADA PARA O LEITOR JUVENIL QUE ELE PRODUZIU APONTA NOVAS FACETAS À REFLEXÃO. DA MESMA FORMA, RECONHECER AS VOZES NEGRAS NA CADEIA LITERÁRIA PRODUZIDA RECENTEMENTE NO PAÍS SE TORNA IMPRESCINDÍVEL COMO DIMENSIONAMENTO DO TEMA.

ABSTRACT: THIS ESSAY AIMS TO SHOW HOW LITERARY WORKS AIMED AT CHILDREN AND ADOLESCENTS OPT FOR THEMATIC THAT EXPAND OUR PERCEPTION OF SUCH TOPICS. FOR INSTANCE, BY CONSIDERING THE POINT OF VIEW FROM WHICH MODELS OF HUMANITY ARE CONSTRUCTED IN A TEXT BY JULES VERNE ONE CAN EXAMINE THE MANNER IN WHICH THE AUTHOR REPRESENTS AFRICANS. PAULA BRITO'S ROLE IN PUTTING TOGETHER A COLLECTION OF TEXTS AIMED AT A JUVENILE AUDIENCE FLAGS UP NEW ELEMENTS FOR REFLECTION. SIMILARLY, WE CONTEND THAT RECOGNIZING THE IMPORTANCE OF BLACK VOICES IN RECENT BRAZILIAN CHILDREN'S LITERATURE IS CRUCIAL TO ESTABLISHING A FULL PICTURE OF CONTEMPORARY WRITING PRODUCED FOR A YOUNGER AUDIENCE.

PALAVRAS-CHAVE: PERSONAGENS NEGROS, EDITORES NEGROS, ESCRITORES NEGROS, LITERATURA INFANTO-JUVENIL, PAULA BRITO.

KEYWORDS: BLACK CHARACTERS, BLACK EDITORS, BLACK WRITERS, LITERATURE FOR CHILDREN, PAULA BRITO. 
leitor criança ou adolescente pode vir a se relacionar com os inúmeros personagens e ambientes de algum universo literário à sua disposição. E quando ele se depara com a voz negra ${ }^{1}$ em alguma parte desse circuito? O âmbito das expressões literárias voltadas para esse público específico merece atenção e se coaduna com o tema mais abrangente.

A amplitude de uma reflexão a esse respeito exigiria muito de um pequeno artigo. Todavia, é possível eleger alguns aspectos sensíveis para eventuais enfrentamentos que provoquem a forma de perceber o assunto. É a proposta deste texto. E já que a pergunta é “quando?”, ela impõe a perspectiva temporal na percepção dos acervos.

\section{O grito do personagem}

Há uma tradição de estudos, locados em diferentes áreas, cujo foco é a presença de personagens que referem uma origem africana nas bibliotecas formadas pelo país. O cotejo da redação com a ilustração vem permitindo isolar, para reparo, a imagem engendrada em ambas as linguagens. Uma perspectiva antropológica considera tais modelos de humanidade construtores de identidades sociais e um polo de argumentos culturais. A elaboração da face, da postura corporal, do lugar onde as figuras foram posicionadas e o seu relacionamento entre as demais em cena, a qualificação atribuída ao cenário, entre outros, são elementos a compor um ponto de vista para a narrativa. Para o analista, o ambiente das páginas deixa pistas acerca do contexto cultural que o engendrou, assim como da resposta particular presente na autoria.

O aspecto inicial a notar é o quanto o exame de materiais produzidos numa época é capaz de também revelar muito sobre outra. Caso apanhássemos da prateleira as Cinco semanas em um balão, viagem de descoberta da África por três ingleses (1863), de Júlio Verne (1828-1905), observaríamos que a África aparece como temática da primeira novela de sucesso do escritor. Júlio Verne entre-

1. "Vozes negras" é uma expressão poética para um significado político. Aqui o uso a insere nos debates acerca das relações de poder na particularidade das dinâmicas do racismo no país. "Negras", como categoria, abrange a identidade relacionada a fenótipos que marcam uma origem continental africana associando a história da escravidão moderna para demandas por equidade para direitos civis. "Vozes" é uma noção interlocutora para os estudos das representações sociais. 
laça, ao longo da ficção, nomes de autores e membros das mais renomadas instituições científicas existentes àquela altura: Livingstone, Burton e Speke, por exemplo. Nos moldes de um relato de viagem, o narrador faz referência aos Boletins da Sociedade Geográfica de Paris, bem como aos da mesma instituição na Inglaterra, para apresentar um personagem imaginário, Doutor Fergusson, que seria membro da Sociedade Real Geográfica de Londres. O balão foi batizado de "Vitória", perfilando os fortes interesses europeus em jogo no continente negro.

Desde a edição original, o gênero de ficção científica oferecido por Júlio Verne retrata os africanos como macacos, por meio dos desenhos e de sugestivas alusões no texto. A despeito do status de Julio Verne, a obra tornou-se um clássico testemunho dos argumentos racistas pautados numa construção europeia da diferença, nesse caso, a africana. A fórmula que consistia em idiotizar o continente negro para exaltar o europeu ecoou entre o público jovem de todo o mundo. No enredo, os africanos bestializados e sem voz, que no máximo proferiam grunhidos, traduziam o esforço de levar a crer que não pertenciam à humanidade.

A revisão incessante de produções desse tipo revelou muito das contingências imperialistas e colonialistas imbricadas neste conhecer o "outro". A evidência do argumento racista das imagens a retirar a voz dos africanos aponta para novas questões se se considerar sua veiculação em obras de sucesso. $\mathrm{O}$ valor alcançado pela obra a mantém nas prateleiras. Hoje, a especificidade de ser dirigida a um público de pouca maturidade ou com poucos elementos para construir respostas, emocionais ou racionais, frente ao argumento violento permite conjecturas. $\mathrm{O}$ texto datado não concebia o africano como eventual público na época. Então, é importante perceber que, embora algumas teorias racistas tenham sido banidas do mundo adulto e refutadas por acadêmicos maduros, elas podiam adquirir, no aparentemente ingênuo formato de livros infantis, canais para fixar preconceitos, estimular estereotipias e evocar atitudes discriminatórias.

A mudança do paradigma desde os originais de Júlio Verne para sociedades como a brasileira desdobra, ainda, outra ordem de questões. O imaginário de outros tempos, como camadas assentadas, continua a repercutir no presente. É como se as imagens cumulativas contribuíssem para uma internalização compartilhada a respeito, por exemplo, do mundo africano. Uma fonte de 
informação poderosa também é uma fonte de sentimentos e necessita de contraponto. A leitura de Cinco semanas... teria um conjunto de outros olhares a formar opinião acerca do mundo africano. Uma biblioteca formada por diversos pontos de vista evitaria os monólogos discursivos sobre a imagem do "outro"; uma questão que esbarra no problema do acesso à produção editorial. Afinal, o embate de ideias e a garantia de espaço para pontos de vista distintos é a forma de requerer democracia para o saber compartilhado. Portanto, a desproporção entre modelos de humanidade, de uma e outra origem continental, disponibilizados para os jovens em formação ainda desafia as sociedades contemporâneas.

Até bem pouco tempo, a referência a passar pelas vistas infanto-juvenis, pautada numa origem africana, asiática, indígena americana, do oriente ou dos polos da terra ficava muito aquém quando cotejada com aquela de origem europeia. E isso parecia natural, ou seja, não recebia qualquer questionamento. A demanda por equidade na representação das identidades sociais, frente à desventura proporcionada por Júlio Verne, gerou respostas como a de tornar o(a) escritor(a) africano(a) um "enunciador". O protagonismo que levaria à valorização da própria história coincidiu com o período das independências africanas ao longo dos anos de 1960. Nesta situação, a voz negra na literatura tomou a cena influenciando processos de afirmação editorial, sobretudo na interlocução com as futuras gerações. Assim como este mote, o histórico das representações que valorizam a origem africana delineia, como tópico de reflexão, o acesso à cadeia de produção editorial.

Permanecendo ainda no século XIX, há outras lições.

\section{A voz alta do protagonista}

Se o primeiro aspecto relevante destacou a presença de uma origem africana surgida nos livros para observar uma autoria, o que dizer de um patamar mais decisivo da cadeia editorial como a edição de livros para jovens leitores, feita por descendentes de africanos? Desta vez podemos recordar a voz negra das precoces investidas de Francisco de Paula Brito, o célebre editor do século XIX. Através de um dos títulos por ele publicado - Fábulas de Esopo. Para 
uso da mocidade, arranjadas em quadrinhas $(1857)^{2}$ - é possível explorar a vertente da presença negra num âmbito importante do campo literário no Brasil.

A historiografia da produção editorial no país invisibilizou, e muitas vezes desqualificou, o empreendorismo desse homem das letras. A pesquisa biográfica tendo como foco um realizador dessa monta adentra o ambiente oitocentista na cidade do Rio de Janeiro. Poderia ser numa das tardes que findavam o ano de 1809, na rua do Piolho quando esta recebia mais um morador. Ali nascia, aos dois de dezembro, Francisco de Paula Brito, filho de Maria Joaquina da Conceição Brito e de Jacintho Antunes Duarte. Mesmo dia, aliás, do aniversário do futuro imperador Pedro II, o que será marcado no nome da Empresa Literária Dois de Dezembro que terá seus estatutos publicados no ano de 1855. Muito antes disso, com 22 anos apenas, Paula Brito adquirira a loja de encadernação e livros de um primo seu. Para os contornos familiares há, ainda, a figura do avô paterno, o ex-comandante do Regimento "dos Pardos” em tempos da administração portuguesa, que viria a ser um reputado ourives de lâmpadas de prata para as igrejas. Dos seis aos 15 anos, o menino havia morado com os pais em Magé. $\mathrm{O}$ avô toureta foi buscá-lo para viver na Corte introduzindo o neto no mundo das profissões da cidade do Rio de Janeiro. Mas, assim que chegou ele já tinha trabalho numa botica. Por pouco tempo. Logo começou na Tipografia Nacional, a sucessora da velha Imprensa Régia de D. João VI. O aprendiz de tipógrafo rapidamente passou a trabalhar com grandes casas impressoras como a Tipografia de R. Ogier e, em seguida para a Seignot-Plancher, cujo fundador também era editor do Jornal do Comércio. Em 1827, portanto, três anos após o menino voltar para o Rio de Janeiro, ele estava contratado pelo recém fundado Jornal do Comércio como compositor tipográfico, assumindo mais tarde o departamento de impressão. De compositor, seguiu como diretor de prensas, redator, tradutor e contista até se tornar proprietário da Tipografia Fluminense de Brito \& Cia. Desde 1831, o fundo de sua casa e, então a livraria, passou a ser ponto de encontro de políticos e intelectuais como José Bonifácio e de literatos como Joaquim Manuel de Macedo, Manuel Antonio de Almeida, José de Alencar e Gonçalves Dias.

2. Publicadas no Rio de Janeiro, pela tipografia Dois de Dezembro, de propriedade de Paula Brito, trata-se de 77 fábulas seguidas de mais 15 , em suplemento, totalizando 375 p. 
Ali nasceu a sociedade lítero-humorística Petalógica. Mais tarde, o então reconhecido editor ganharia certo destaque ao publicar, em 1855, o poema de um rapagote de dezesseis anos, Machado de Assis, na sua revista Marmota Fluminense. Machado de Assis voltaria à Livraria Paula Brito, em 1858, como revisor e colaborador da Marmota.

Este excerto biográfico serve para apontar a densidade da história de vida de um certo habitante do Rio de Janeiro. Sobretudo, o empreendorismo nas letras de uma família descendente de africanos. Outros detalhes apontam a rede de sociabilidades não apenas literárias. $\mathrm{O}$ avô de Paula Brito era famoso por seus lampadários de prata e por ser discípulo de Mestre Valentim, outro habitante negro de importância no período, e que lhe ensinara o ofício da torêutica, ou seja, a arte de trabalhar os metais. Martinho Pereira Brito havia se alçado ao posto de comandante do $4^{\circ}$ Regimento de milicianos, também chamado "dos pardos", num tempo em que se separavam os batalhões pela cor da pele. Estas pequenas nuanças permitem ao analista estabelecer relações.

Noutra frente, para melhor compreender a esfera de atuação de um agente do ambiente editorial numa época em que a sensibilidade literária era para poucos, há uma gama de impressos realizados por Paula Brito dentre os quais destaca-se o jornal. O homem de cor, publicado em 1833, ou ainda Memória para melhorar a sorte de nossos escravos (1845), de autoria de Caetano Soares. Da mesma forma, deve-se considerar o domínio de tecnologias do período. A litografia, uma novidade surgida na Alemanha na virada do século XVIII para o XIX, mas conhecida apenas a partir dos anos 1820, foi introduzida na empresa de Paula Brito editor desde o início de suas atividades. Outros tantos elementos poderiam aprofundar o conhecimento das circunstâncias que engendraram uma biografia singular, por tanto tempo desconhecida. Algumas pesquisas revelam que ao empresário Paula Brito não passou despercebido o público juvenil, ${ }^{3}$ para o qual ele destinaria obras de cunho educacional como atesta a publicação das Cartas do professor da roça. Artigos relativos à instrução pública da corte (1864), de Manoel José Pereira Frazão. O editor também se apresenta como impressor da Casa Imperial e editor exclusivo do Colégio Marinho.

3. Cf. Maria Eunice Gondim. Vida e Obra de Paula Brito. Rio de Janeiro: Brasiliana, 1965; e mais recentemente, RAMOS JR, José de Paula; DEAECTO, Marisa; MARTINS FILHO, Plínio. Paula Brito: editor, poeta e artifice das letras. São Paulo: Edusp; São Paulo: Com Arte, 2010. 
No entanto, seções de entretenimento refletem a atenção do editor também para com o público feminino, como o demonstra o anúncio da Biblioteca das senhoras (1858) [figura 1]. Os dois volumes desta abarcam textos extraídos de outra obra - A moral da infância - "escolhidos pelo editor para instrução e recreio da mocidade” (RAMOS JR, J.; DEAECTO, M.; MARTINS FILHO, 2010, p. 163):

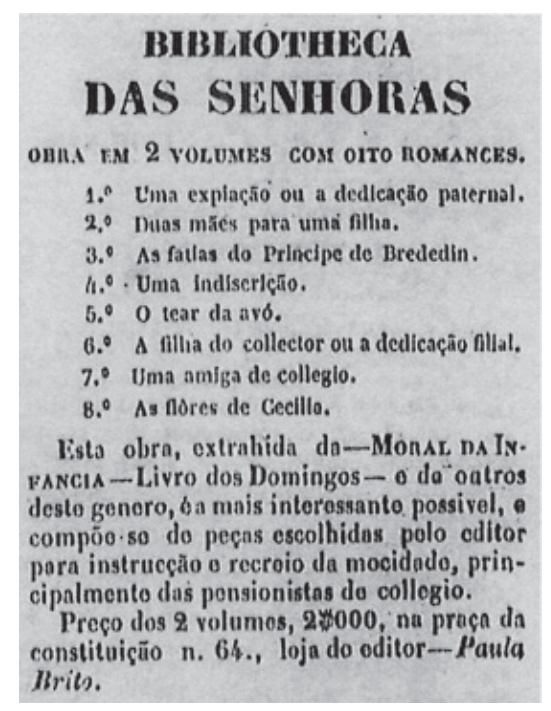

Fig. 1: Biblioteca das senhoras (1858).

O estudo de caso com produtores negros no setor revela que constituem vozes negras na produção literária. O fenótipo é um diferencial numa sociedade que hierarquiza diferenças de aparência. Considerar o modo como Paula Brito respondeu às circunstâncias de seu tempo é ampliar a percepção e dar referência à população marcada pela africanidade. Pontuar o protagonismo é ir além da marca de perdedor social que fica à mercê de representações sociais hediondas.

A história de vida cruzada com os acontecimentos editoriais no país e com a especificidade do público infanto-juvenil, às vezes, faz aflorar significativos pormenores. Como, por exemplo, o dado que chamou a atenção: as Fábulas de Esopo publicadas por Paula Brito. 


\section{Uma voz fabulosa}

Esopo é, ao mesmo tempo, um personagem, um enunciador, promotor de certo gênero literário e, sobretudo, uma referência do mundo grego. Embora passíveis de problematização, as biografias legendárias em fontes antigas ao menos atestam não ter Esopo passado despercebido para o historiador Heródoto nem para Aristóteles ou Plutarco. Notícias sobre ele remetem à Grécia no século VI a.C. e sugerem tratar-se de um escravo pertencente ao filósofo Xanto que teria conquistado a liberdade graças à astuta inteligência. A maior prova dela estaria nas fábulas a ele atribuídas. O filósofo Demétrio de Falera (345-283) envolvido na organização da biblioteca de Alexandria, no Egito, teria copilado o repertório antes difundido em louças, estampas ou manuscritos.

Esopo congrega um feixe de simbologias. Dentre os elementos de sua biografia esparsa no tempo surge a Frígia das cartografias antigas, região da atual Turquia, de onde ele teria vindo para então chegar à Grécia. A conexão apareceria no manuscrito anônimo Aesop Romance surgido no século I da era cristã, mas que receberá novas versões medievais. Mesmo a moderna denominação bonnetphrygien (barrete frígio), um item da indumentária do antigo reino da Frígia, foi recuperado da Antiguidade, transformando-se num dos ícones da Revolução Francesa setecentista. Grosso modo, na polis grega, e depois também costume entre os romanos, os libertos tornados cidadãos deveriam portar a vestimenta, uma espécie de barrete usado na cabeça, sinônimo de liberdade. Esta ambiguidade entre ser liberto e escravizado numa dinâmica que resulta na liberdade são elementos para um tema de ocasião.

Da história de vida do escravo que se liberta, a informação mais preciosa, no entanto, está na informação que empresta uma face negra etíope ao famoso grego. Maximus Planudes (1260-1305), teólogo bizantino, teria difundido essa abordagem com hipóteses etimológicas para os vínculos entre as palavras 'Aesop' e 'Aethiopian'.

Um pequeno livro de 11,2 x 6,5 cm, versão bilíngue, em grego e latim publicado no ano de 1564 - Aesopi Phrygis Fabulae apud Hieronymus de Marnef - permite conferir a identidade aludida. Mais rapidamente, outra versão de 1570 disponibilizada eletronicamente pela Open library oferece o acesso ao diálogo entre Xantus e Aesop. “ - (...) cuiu es? Ile: Níger.” [Figura 2]. 
As traduções para o inglês referem estar a aparência de tintura negra associada ao seu nome. E também o fato de que, ao ser indagado sobre sua origem, Esopo teria respondido: "Eu sou negro".

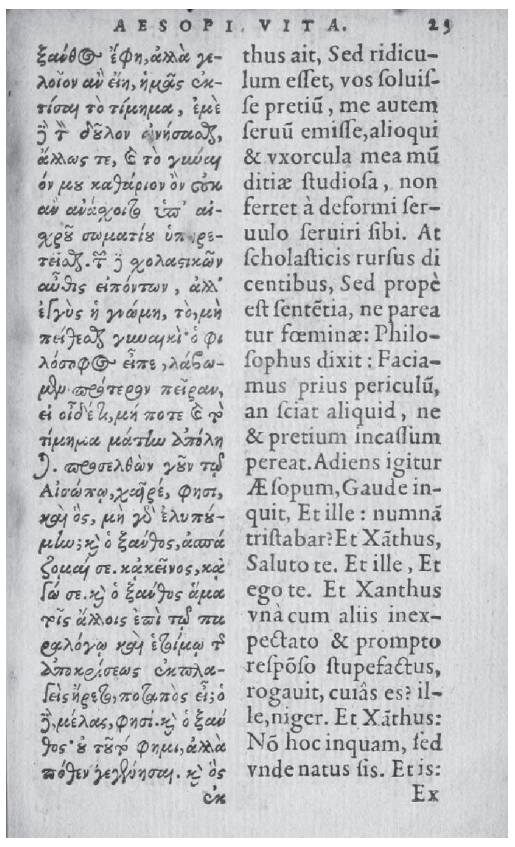

Fig. 2: Aesopi Phrygis Fabulae apud Hieronymus de Marnef (1570).

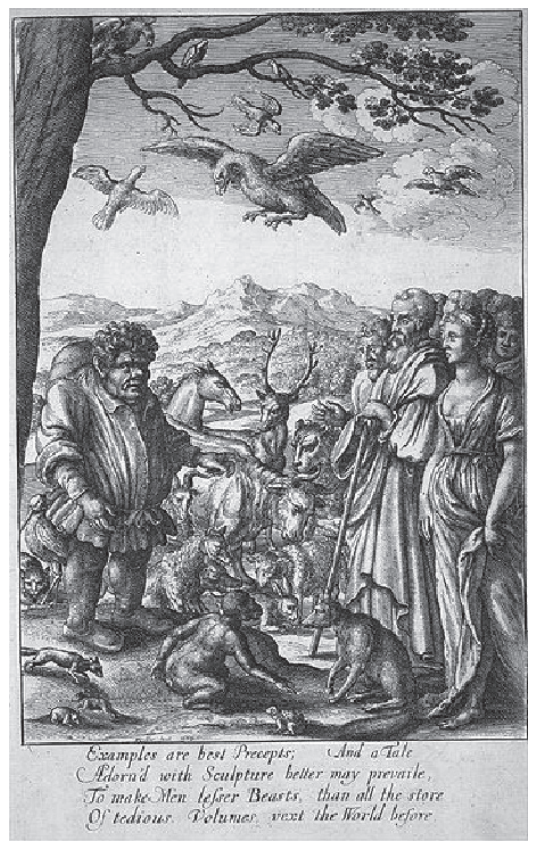

Fig 3: Wenzel Hollar (1607-77).

Esopo. Acervo de livros raros da biblioteca Thomas Fisher, Universidade de Toronto, Canadá.

A possibilidade de ser Esopo um negro africano remeteria aos estudos da comunicação entre o norte da África e a Europa na Antiguidade nas trocas com o Oriente. Por outra via, a associação com a África, da mesma forma imediata, explora o liame entre os animais das fábulas de Esopo e os das narrativas orais tradicionais no continente negro. Certamente a restituição de um vínculo desta ordem requer uma série de medidas cautelares.

Contudo, e mais especialmente abaixo do Magrebe, há uma tradição de narrativas curtas, bem humoradas e relacionadas ao cotidiano e com fins morais sendo os animais espelho das ações humanas. Qualquer pesquisa nessa 
inspiração além de sobrepor aspectos temporais, tem para considerar, com a mesma importância, os aspectos geográficos.

Teria sido Esopo um griô africano? Antigos bardos, uma espécie de musicistas que cantavam ou recitavam, transmitindo a história de seu povo não foram exclusivos do ambiente europeu. Notícias de bardos negros a andar por entre os remotos reinos do noroeste africano foram registradas por estrangeiros. A ideia moderna de griô advinda de uma longa tradição relaciona o fato de ele pertencer a uma casta de memorialistas excepcionais na arte de manipular a palavra. Numa delas, o Mande, sobre a qual há relatos desde o século VIII de nossa era, o griô pertenceria à casta dos Niamakalas a quem cabia o saber acerca da energia espiritual chamada niama. Dentro dessa organização social, a casta do ferreiro controlava os níveis de niama presente nos minerais. Havia, ainda, a dos homens do curtume que sabiam controlar niama, uma vez que a força vital e o poder dos animais ficavam retidos no couro, sendo libertados na sua manipulação. E, sobremaneira, os mandingas acreditavam que as palavras possuíam altos níveis de niama. Os griôs eram educados para conhecer os níveis perigosos de niama e controlar esse poder. Como mestre da palavra, o griô poderia ser um exímio conhecedor dos provérbios. Mas atrás do genealogista, diplomata, instrumentista, havia o sábio conhecedor das estações ou do segredo das máscaras místicas e ações sacerdotais. Entre todos havia aquele de grande poder que tinha a interdição ritual de nunca mentir ao utilizar a palavra. O uso faz vibrar suas forças interiores. Essa força renasce na língua. Por isso ele não emprega a palavra imprudentemente. A força vital tão interior pode ser perturbada pela mentira, o que expõe o alto valor para com a verdade.

Já para os griôs trovadores, menestréis que exercem a arte de contar histórias, o compromisso com a verdade é de outra ordem. A tradição lhes concede o direito de embelezar os fatos, desde que consigam divertir ou entreter o público que seduziram. Muitas vezes, com música e coreografia devem levar à compreesão de verdades antigas. Dessa forma, aparentemente divertida, podem até denunciar os desonestos e os ladrões indicando, assim, o exemplo a ser seguido. Atrás da distração, o sábio foi treinado para aprofundar os saberes sobre a natureza secreta, seja humana, animal ou social. O aprendizado acontecia aos poucos, mas integrado ao dia a dia. Uma pequena fábula poderia ensinar sobre as virtudes, a audácia, a valentia, a solidariedade, a coragem, 
o amor à verdade etc. E o repertório de pequenas histórias era largo, uma para cada momento. O estrangeiro chamava de arte da oratória. Mas o que o griô exercitava na sua aldeia era a arte de receber e transmitir conhecimento de um modo muito peculiar.

Esopo também ficou conhecido pela habilidade com as palavras. Há um provérbio milenar mandinga que diz "A língua não tem osso, mas pode quebrar um esqueleto" significando que a palavra é poderosa também para destruir.

A quem levar em conta o texto popular que Fernando Kitzinger Dannemann disponibiliza na internet ${ }^{4}$, o reconhecimento de Esopo como um griô seria de fácil alcance:

Uma circunstância da vida do fabulista deu origem à locução 'as línguas de Esopo'. Diz-se que certo dia o seu senhor - Xanto - o encarregou de buscar no mercado o que de melhor encontrasse para servir como refeição a alguns convidados. Esopo saiu e comprou um punhado de línguas bovinas, que mandou preparar de várias maneiras. Durante a festa, e na medida em que elas iam sendo servidas aos convivas, estes deixavam transparecer cada vez mais o seu desagrado, e em breve alguns deles, aborrecidos, passaram a reclamar. Questionado, Esopo justificou-se:

- Há coisa melhor do que a língua? Ela é o laço da vida, da razão; e por meio dela as cidades são construídas e policiadas. Graças a ela as pessoas não só são instruídas, persuadidas e convencidas nas assembléias, mas também cumprem o primeiro de todos os deveres, que é o de louvar a Deus.

- Está bem - replicou Xanto, que pretendia embaraçá-lo. - Pois amanhã eu quero que você compre o que houver de pior.

No dia seguinte Esopo serviu novamente línguas, apenas asseverando que a língua é a pior coisa que há no mundo:

- A língua é a mãe de todas as questões, a origem de todos os processos, a fonte das discórdias e das guerras. Se por um lado ela é o órgão da verdade, de outro

4. Fonte: http://www.recantodasletras.com.br/biografias/621597. Consulta em 05 de junho de 2010. 
é também o do erro e, pior ainda, o da calúnia e da infâmia, porque se em dado momento ela louva os deuses, em outro é usada para a blasfêmia e a impiedade.

Apenas a sugestão de que Esopo representa uma voz negra já causa um impacto de grandes proporções. A proposição existe desde há muito tempo, embora raramente aventada. Podemos então lançar uma pergunta para reflexão: se considerássemos um Esopo negro ao invés de grego, que diferença isso faria na história literária mundial enquanto percepção do acervo precioso de fábulas na história literária mundial hoje voltado para o leitor infantil e juvenil?

\section{Concluindo com alguns exercícios para a voz}

Ampliar o entendimento acerca das vozes negras abrange inúmeros caminhos. A nuança dessa voz por toda a cadeia produtora do literário redimensiona o olhar sobre o objeto a perseguir. $\mathrm{O}$ foco acerca da representação cultural dos personagens procura revelar o ponto de vista que os elaborou. Esta busca fornece elementos para os debates envolvendo a construção da identidade-alteridade. Mas os personagens que habitam páginas e os que as produziram ainda precisam ocupar espaços nas historiografias que abranjam o circuito editorial e a origem africana. Vale notar que esse cruzamento requer uma nota de pé de página que diga respeito à invisibilidade ou desqualificação submetida a empreendedores da envergadura de Paula Brito. Basta rever como ele foi posicionado na historiografia do seu ramo de atividade; posição da qual nos últimos tempos se tenta resgatá-lo.

A jornada dos heróis das letras tem dado sinais de uma existência fértil para estudos e pesquisas. É preciso reconhecer avanços. Escritoras como Geni Guimarães cativaram o leitor e a crítica, duas dimensões dessa mesma matéria. Nascida no interior de São Paulo ela busca a memória da menina das fazendas reconstruída com afetividade no $A$ cor da ternura. A obra foi capaz do feito extraordinário de receber, entre outros, o prêmio Jabuti, em 1990. Façanha repetida por Joel Rufino, premiado em 1991 e 1992, além de ser a indicação brasileira ao Troféu Hans Christian Andersen, o mais importante prêmio internacional de literatura infanto-juvenil, o que se deu em 2002, sendo o autor também um dos quatro finalistas em 2004. Outro prêmio de impor- 
tância, o Barco a Vapor, contemplou o jornalista Delcio Theobaldo, em 2008, que concorreu com Pivetim superando outros 540 títulos inscritos. O trabalho também foi agraciado pela APCA de 2009, na categoria Literatura Infantil/ Juvenil. O conhecido pesquisador do jongo arquitetou um texto carregado de imagens sensórias para contar uma história de amor juvenil que percebe um lado invisível da cidade. Também é relevante citar alguns dentre os ilustradores e suas vozes negras. Nomes como o da mineira Denise Nascimento com concepções de extrema delicadeza. Destaque também para o encontro da escritora estreante Meire Cazumbá com Marie Ange Bordas para o Histórias de Cazumbinha (2010). Valorizada na autenticidade de suas memórias às margens do São Francisco aborda, de modo inovador, a temática dos quilombos. O trabalho gráfico articula fotografia e desenhos das crianças do Rio das Rãs. Projetado pela artista que não é negra, mas tem feito ressoar vozes negras a partir de vivências multiculturais como os campos de refugiados em Kakuma no Quênia, a obra divide a autoria e a sintonia.

Há inúmeros artistas lançados pela editora Mazza, que se propõe afirmativa para o repertório afro-brasileiro. Desse núcleo desponta a obra Omo-Obá: histórias de princesa, escrita por Kiusam de Oliveira. A qualidade do texto baseado em referência mítica reúne seis pequenas histórias de divindades iorubas femininas. Todas são princesas que se tornarão, mais tarde, rainhas. A autora encontrou uma forma de falar da capacidade de empoderar meninas de todos os tempos. Gênero e o assunto religioso de origem africana alcançam o primor do literário e do lúdico. As divindades brincam e uma atrai a outra para descobertas. A abordagem sem estereotipia ou fórmulas clichetescas chama a atenção da criança leitora para a intimidade, o contato com um poder interno, que é segredo e é sagrado. Porém, sem a condenação do masculino.

Merece destaque a profícua produção de Júlio Emílio Braz, autor de mais de 150 obras, além das adaptações de obras estrangeiras. Foi agraciado com o Austrian Children Book. Award, na Áustria, pela versão alemã do livro Crianças na Escuridão (1991) e o Blue Cobra Award, do Swiss Institute for Children's Book, com o mesmo livro. Ruth Guimarães, nome imortal da Academia Paulista de Letras, também ilustra-se como tradutora.

Obras como Os nove pentes d'África de Cidinha da Silva, A noite dos cristais de Luis Fulano de Tal, o singelo Bruna e a Galinha de Angola de Gercilda de Almeida, Tear africano de Henrique Cunha Jr, além das produções de vários au- 
tores como Edmilson de Almeida Pereira, Lia Vieira, Mãe Beata de Yemonjá, Martinho da Vila, Mestre Didi, Nei Lopes, Helena Teodoro, Rogério Andrade Barbosa, Nilma Gomes, Rosa Andrade, Osvaldo Faustino etc. fazem ecoar vozes negras sob inúmeros aspectos. Todos enfrentam questões comuns como a imposição dos branqueamentos ou a restrição aos repertórios que os identificam. Para adensar o conhecimento, basta serem lidos e ouvidos, não como essência estática e, sim, em sua complexidade reveladora do único.

\section{Referência bibliográfica}

RAMOS JR, José de Paula; DEAECTO, Marisa; MARTINS FILHO, Plínio. Paula Brito: editor, poeta e artifice das letras. São Paulo: Edusp, São Paulo: Com Arte, 2010

Recebido em 10 de julho e aprovado em 25 de setembro de 2010. 